\title{
PROTOTYPE DESIGN SYSTEM FOR MOBILE WEB USING RADIO FREQUENCY IDENTIFICATION AT PARKING BUILDING
}

\author{
Derwin Suhartono, Chitra Patricia, Hendry Steven and Kevin \\ Department of Computer Science, School of Computer Science, Bina Nusantara University, Jakarta, Indonesia
}

Received 2013-04-24, Revised 2013-06-25; Accepted 2013-07-26

\begin{abstract}
Several factors cause people forget things. They are retrieval failure, interference failure to store and motivated forgetting. So, it is considered to have tools in order to prevent those. This happens almost everywhere, including when the drivers forgot where their car has been parked. Furthermore, the increase of parking fee is also considerable. The purpose of this research is to design a prototype system for mobile web as one of the helpful tools for car parking location reminder using Radio Frequency Identification (RFID) technology that implemented at the parking building. The research is conducted by direct observation of the current system, do a comparison of similar applications, design the architecture of the system, make the programs, create a mock-up and mobile web as a prototype. The result of this research is a prototype of parking location reminder using RFID-based on mobile web. The mobile web displays information menu such as the location and the parking information. Based on the research, it is concluded that the mobile web can be used as one of solutions for parking location reminder and allows users to view information such as the parking duration and the parking fee estimation.
\end{abstract}

Keywords: Prototype, System, Mobile Web, RFID, Parking Building

\section{INTRODUCTION}

According to Loftus (2012), one of the world's most renowned experts on human memory, humans have four major reasons why forgetting occurs. Those four factors that cause people often to forget are the retrieval failure/decay theory (disability to remember something because the trace of memory about that thing has been removed), interference: proactive and retroactive (disruption against the thing that will be remembered), failure to store (a thing that will be remembered again but has never been stored in memory) and motivated forgetting (cannot remember something because the brain is deliberately omitted from the memory due to factors such as trauma).

Based on the data from Kompas Media (2011) that is adopted from Jakarta Transportation Agency, it is stated that the number of vehicles is increasing each year.

Based on Jakarta Governor Regulation $120 / 2012 /$ September $18^{\text {th }}, 2012$, the car-parking fee increases to Rp. 3.000,00 up to $\mathrm{Rp} 5.000,00$ for one hour and Rp. 2.000,00 up to $\mathrm{Rp} 4.000,00$ for the next one hour (Table 1). The data shows us that the time is being very valuable right now.

Currently, the existing parking system in Indonesia, especially in Jakarta, only serves to record the entry and exit of motor vehicles, especially cars. Based on the existing system at the moment, it needs a better system development in order to allow cars user to simply find the parking location and access parking information rapidly.

Table 1. Car Growth in 2007 to 2011 Period in Jakarta (Kompas Media, 2011)

\begin{tabular}{ll}
\hline Year & Number of cars in Jakarta \\
\hline 2007 & \pm 2.200 .000 \\
2008 & \pm 2.300 .000 \\
2009 & \pm 2.400 .000 \\
2010 & \pm 2.500 .000 \\
\hline
\end{tabular}

Corresponding Author: Derwin Suhartono, Department of Computer Science, School of Computer Science, Bina Nusantara University, Jakarta, Indonesia 
The research objective is to design a mobile web application to provide car park location by using RFID technology. The features inside the application are park location and its map, entry time, parking duration and estimation of parking fee. It combines hardware and software technology. The research benefits are to help users finding their park location, estimate parking fee and the reliability as it is able to be accessed by anyone, anywhere and anytime by using mobile web.

\section{CURRENT WORKS}

Kianpisheh et al. (2012) has developed a similar system in managing parking area. As seen in Fig. 1, the system assists the vehicle users to find a parking spot on a building. Smart parking system uses sensor-based detector, it is ultrasonic detector. Ultrasonic detector is used to determine whether a parking location on a building has been occupied or not. This sensor will work by releasing sound waves at a frequency of 25-50 $\mathrm{KHz}$. The sound waves will then be in contact with the floor on the parking location so that the reflection of the results will be known whether the parking location can be filled or not.

On the other hand, Rashid et al. (2012) construct an automatic parking management system that uses license plate recognition as the main system. Car plate recognition is done by using several methods such as the gradual recognition of the license plate size, character segmentation on the plate to get the proper character and the normalization process to the segmented characters. The result of the process is then displayed on the user interface collaborated with other supporting information. Figure 2 displays the screen of the application mentioned above.

Yusnita et al. (2012) made a system to determine the availability of parking location based on image processing. The system uses a 5 modules consists of

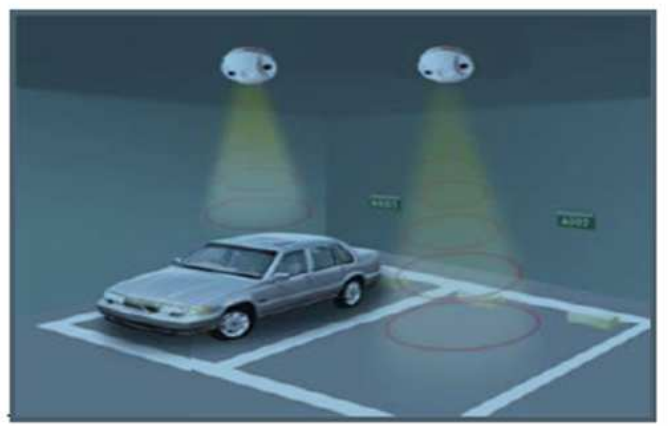

system initialization, image acquisition, image segmentation, image enhancement and image detection module. Each of these modules is done sequentially so that in the end will get the image which is then used to detect whether the parking location has been occupied or not. Results of the image processing will also be displayed in the user interface look at (Fig. 3).

The car will go to look for the location of existing parking area. After getting the desired parking location, vehicle image will be captured by the camera and it will do the analysis based on the modules that have been made before. Once after the module analysis has been completed, the results of it will be displayed in the user interface along with other supporting information.

Reve and Choudhri (2012) have developed a system by using wireless sensor network. The sensor used is infrared sensor (IR) to detect the presence of vehicles and to send the information to the AVR controller. In the AVR Controller component, the central processor will receive the signal from the IR sensor in order to know the status in the parking lot. IR sensor then sends a signal to the AVR controller for processing and sending information back to the IR sensor. The information exchange makes the central processor knows the parking status and Light-Emitting Diode (LED) in the parking lot will turn on or dim. Figure 4 describes the interface of the system.

The closest recent work to our research is the one which was conducted by Mulajkar et al. (2011). Figure 5 illustrates the constructed system. RFID is used as the technologies that support the parking system here. RFID issued the radio waves within massive waves that vary according to the used RFID and after that the generated waves will be captured by RFID tags. RFID system will first gather information from any existing readers and the RFID server will then communicate with the circulation system.

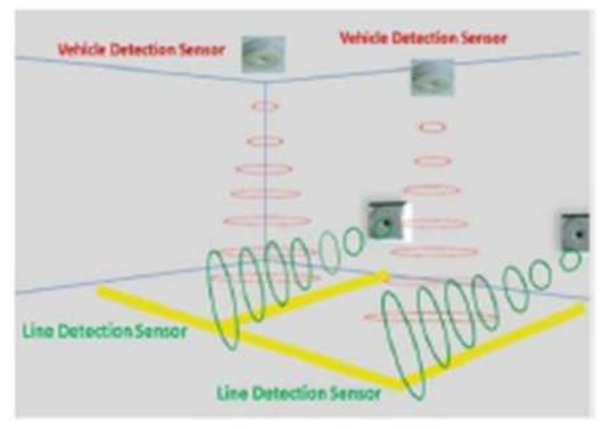

Fig. 1. Smart parking system architecture using ultrasonic detector 
Derwin Suhartono et al. / Journal of Computer Science 9 (9): 1217-1223, 2013

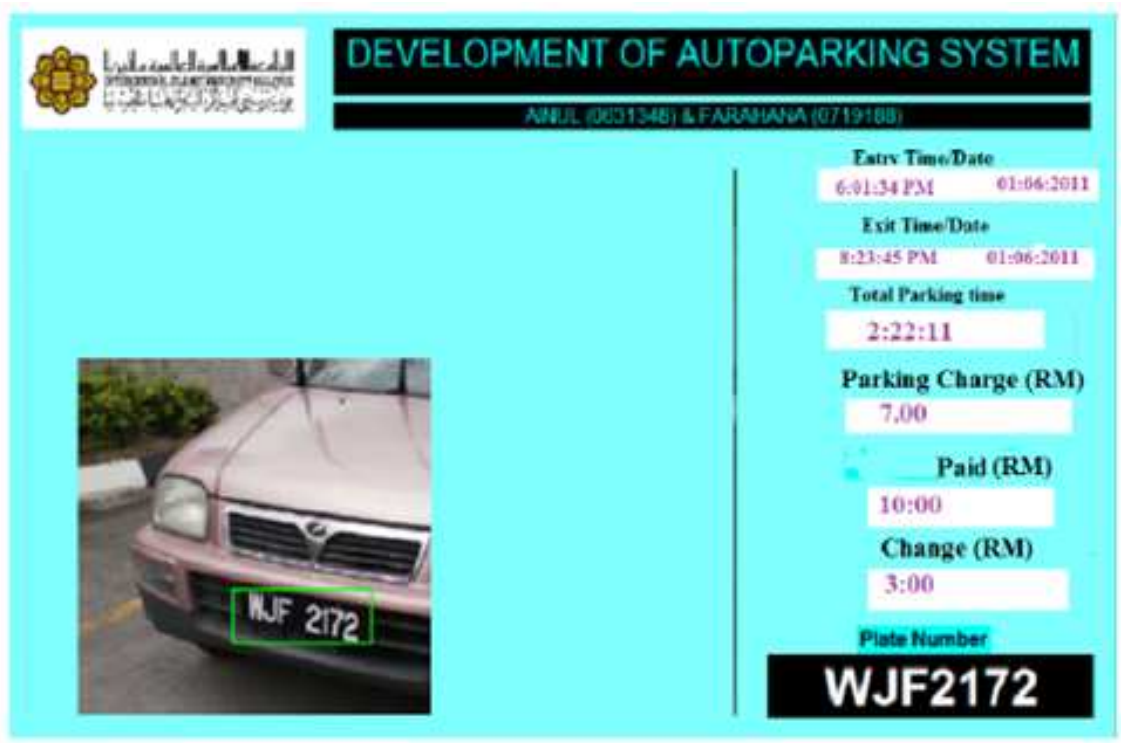

Fig. 2. Automatic parking management system and parking fee collection based on number plate recognition
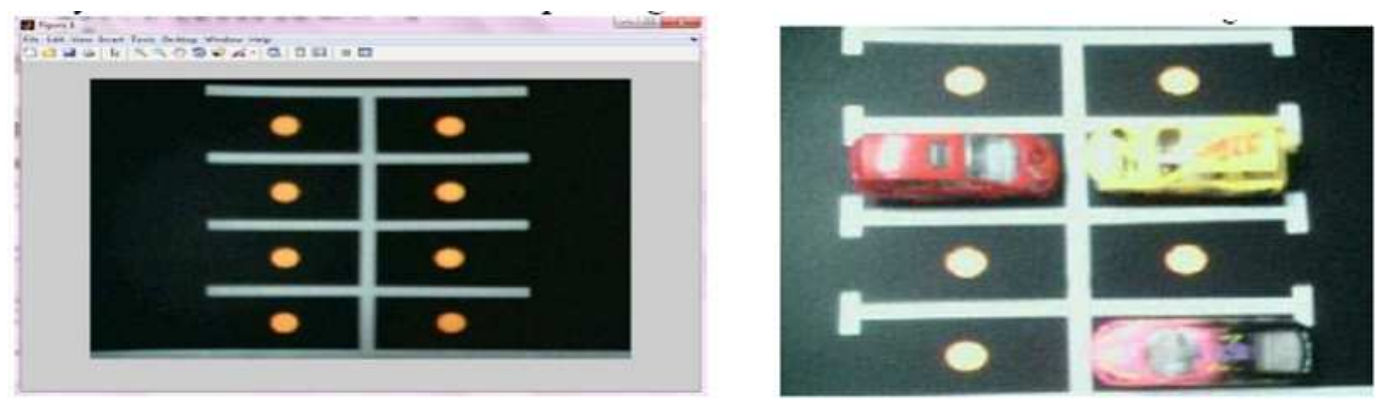

Fig. 3. Automatic parking management system and parking fee collection based on number plate recognition
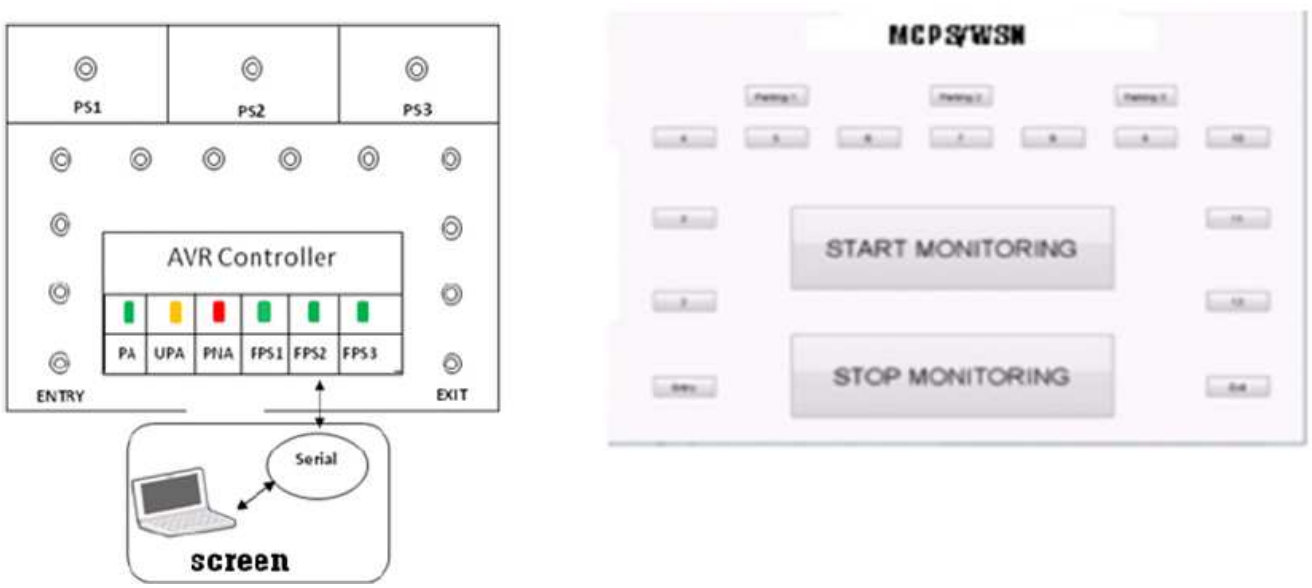

Fig. 4. Management of car parking system using wire-less sensor network 


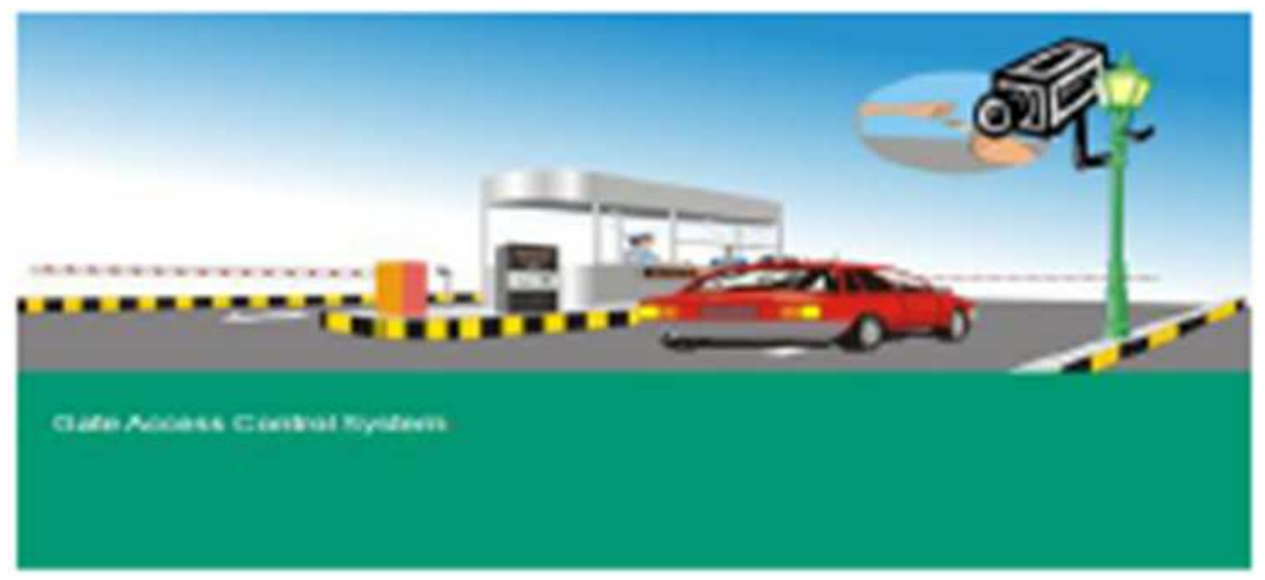

Fig. 5. RFID technology for parking

\section{PROPOSED SYSTEM}

According to the needs analysis from some articles and refers to the previous works, it is concluded that the system which needs to be developed is formulated as follows:

- RFID technology is used in the parking system

- RFID technology is integrated with mobile web through database so that it can save park location

- Navigation mechanism on the mobile web is designed in a simple way. Hopefully it can make users easy to access the information

- Show the parking information in term of its location, park duration and estimation of parking fee

There are 2 main subsystems that are connected each other as depicted in Fig. 6. The first system is the mobile web which is used to see the information about parking location and parking fee estimation. The second, without internet, is the parking system. It is used to manage the parking system which involves the usage of RFID Fig. 7.

The workflow of our proposed system is described as follows.

\subsection{The Car Enters the Parking Building}

- Driver enters the parking building

- Driver presses the button on the card dispenser/machine

- Machine releases the card for the driver

- System gets the time entry and puts the data into the card
- The data will be updated on database server

\subsection{RFID Reader Reads the RFID Card}

- Car goes through the RFID reader then the region will be updated

- RFID reader's sensor runs automatically

\subsection{The Driver Parks the Car}

- After the car has been parked on the location, then the level and row of location will be updated on the database server

- System saves the location on the database

\subsection{The Driver Forgets the Car Park Location}

- Human often forgets things. Car park location is one of the things that is usually forgettable

\subsection{The Driver Access the Mobile Web by Using Mobile Phone}

- As long as the mobile phone has Internet connection, the driver can access the mobile web

- The driver inputs the ticket number contains two letters for the initials of the building and four numbers for the card number

- The system will do authentication and authorization to the ticket number

- The information will be shown after user has been successfully logged in. The information contains location, time entry (time server), duration and estimation fee 


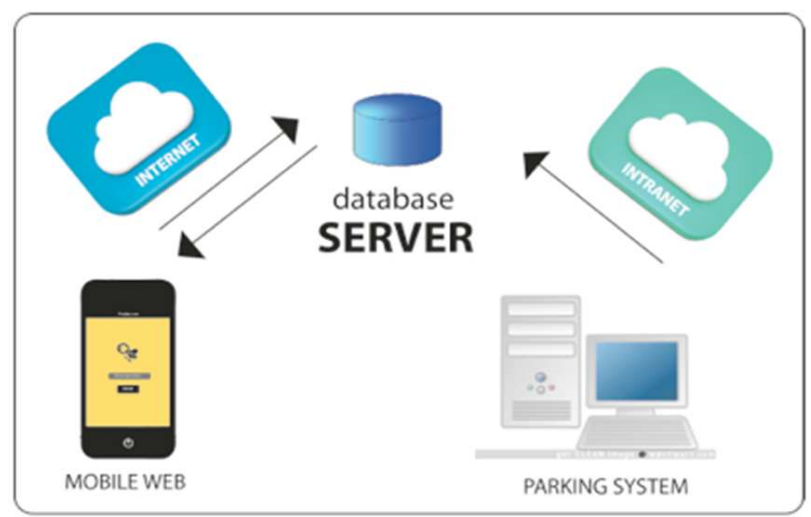

Fig. 6. System architecture of parking system

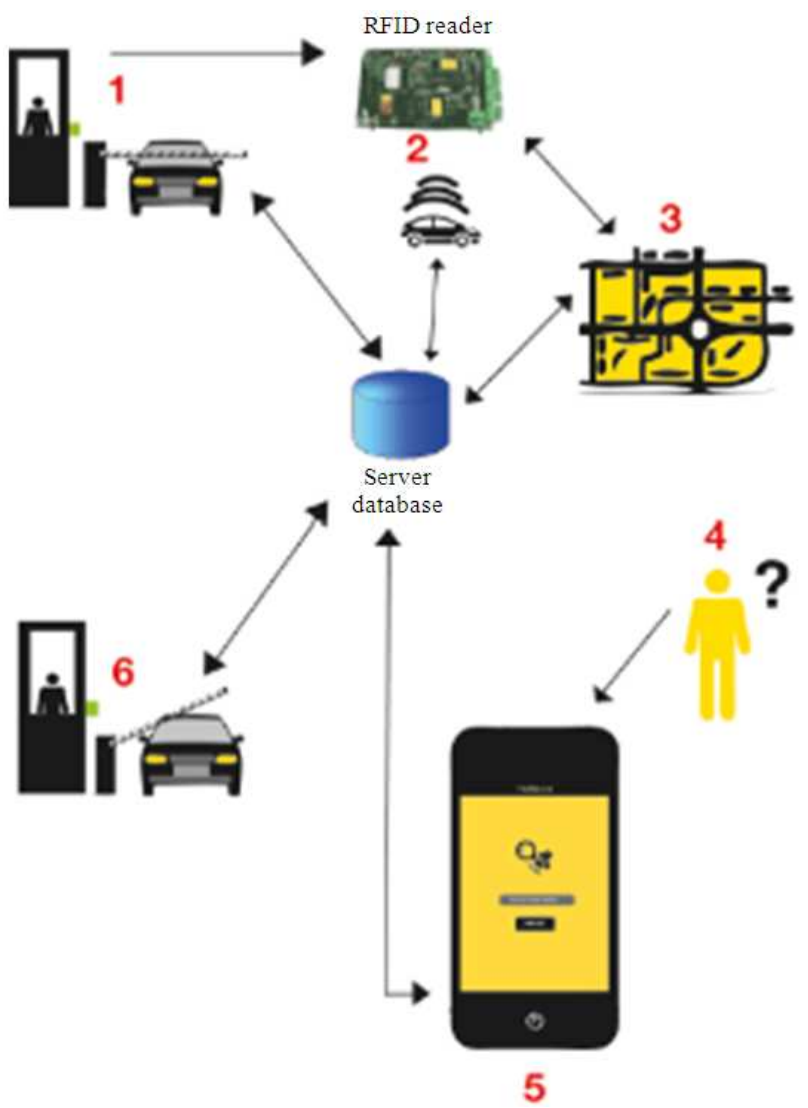

Fig. 7. System workflow of parking system

3.6. The Driver Drives the Car to Exit from the Parking Building

- Driver gives the card back to the employee

- Employee scans the card and the system will calculate and show the parking fee

- Driver pays the parking fee

Exit gate is opened. The system will update the data and move the data to the log. 


\section{RESULTS}

The results from the system development of mobile web consists of two application. They are user (car driver) mobile web and admin web. In addition, there is another one support system called as the parking system. The parking system runs behind admin and user systems and also manages the database server.

\subsection{User Mobile Web}

The first application to support the prototype of the parking system is the user mobile web.

Figure 8 shows the pages of user mobile web. The left side is the first page when user accessed the URL site. User has to input the ticket number that shown in the card. The other pages are the main pages that display the car location and car information. In the middle side, it shows car location details that contain level, row and map of the car park location. The red color on the map shows the region of the car park location. The right side is the car details information that contain ticket number, date and time entry, current time (time server), parking duration and estimation fee that will be paid (depends on the timeserver as user checked the mobile web).

\subsection{Admin Web}

Figure 9 shows the pages of admin web. The left side is the first page when admin accessed the URL site. Admin has to login first by using the username and password. Meanwhile, the right side is the log menu that admin can search data by date. The system shows log information based on the date that has been inputted before.
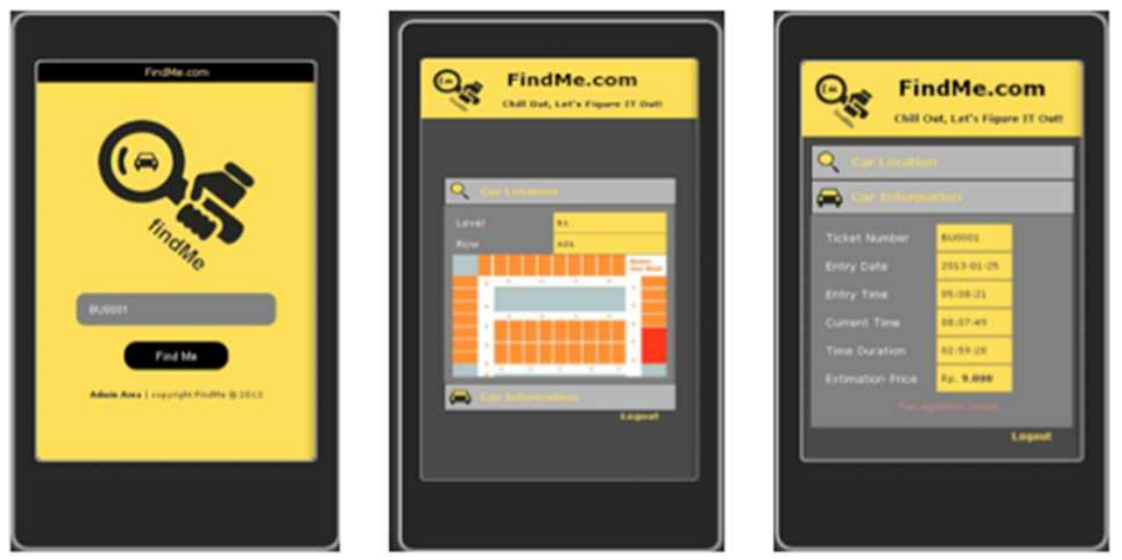

Fig. 8. User mobile web interface
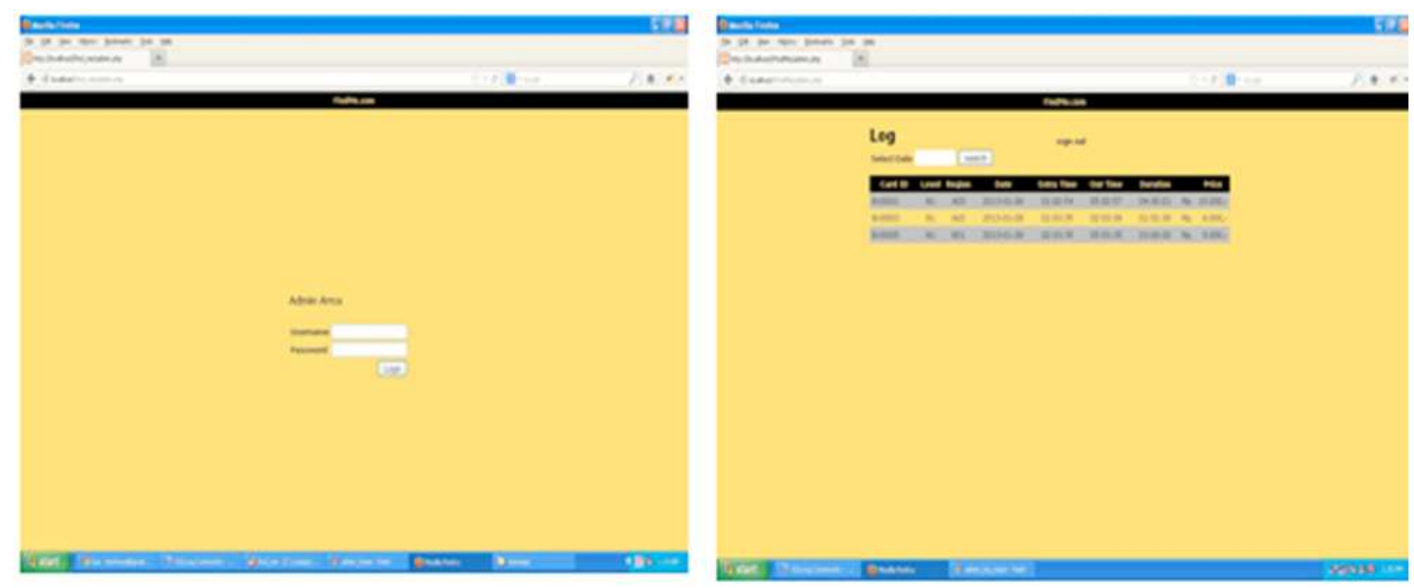

Fig. 9. Admin web interface 


\subsection{Parking System}

Actually, the parking system works behind the interface, but it is the core of the whole system. The parking system will be updated according to this situation:

- Card dispenser will release a card after it has been pressed and then the system will update the time entry in database

- RFID reader reads the RFID card and the system will update the region

- RFID reader reads the RFID card again and the system will update the region continuously until the car driver gets the park

- The car will be detected by the system (in this case, the car is detected by weight pressure plate) and then the system will update the car park location

- The system calculates parking fee based on how long the car has been parked

- When user leaves the exit gate, the system will update the card data (transfer the data to log and reset the data on card)

\section{CONCLUSION}

Based on the research, the conclusions that can be adopted are:

- The system can be used as one of solutions that fulfill user requirement to inform car park location. It is quickly accessed, simple and easy to use

- It provides the useful parking information such as location, map, time entry, parking duration and estimation fee

- The storage system designed using RFID that implemented on parking building mock-up with 1:200 scales

- Collaboration between hardware and software by using RFID technology and mobile web is possible and able to result on high usability application

\section{REFERENCES}

Kianpisheh, A., N. Mustaffa, P. Limtrairut and P. Keikhosrokiani, 2012. Smart Parking System (SPS) architecture using ultrasonic detector. Int. J. Soft. Eng. Applic., 6: 51-58.

Kompas Media, 2011. Tiap hari bertambah 1.068 Motor dan 216 Mobil. Kompas Cyber Media.

Loftus, E., 2012. Explanations for Forgetting, Reasons Why We Forget. About.com.

Mulajkar, R.M., A.P. Phatale and P.H. Kulkami, 2011. RFID technology for parking. Proceedings of International Conference on VLSI, Communication and Instrumentation (VCI' 11), pp: 12-16.

Rashid, M.M., A. Musa, M.A. Rahman, N. Farahana and A. Farhana, 2012. Automatic parking management system and parking fee collection based on number plate recognition. Int. J. Mach. Learn. Comput., 2: 93-98.

Reve, S.V. and S. Choudhri, 2012. Management of car parking system using wireless sensor network. Int. J. Emerg. Technol. Adv. Eng., 2: 262-268.

Yusnita, R., F. Norbaya and N. Basharuddin, 2012. Intelligent parking space detection system based on image processing. Int. J. Innovat. Manage. Technol., 3: 232-235. DOI: 10.7763/IJIMT.2012.V3.22 